\title{
The Effect of Branched Chain Amino Acids on the Synthesis of Isoleucine from Threonine and Pyruvate in Crude Extracts from Escherichia coli
}

\author{
RAIMO RAUNIO and RIITTA ELFVING \\ Department of Biochemistry, University of Turku, Turku 2, Finland
}

\begin{abstract}
The effects of the branched chain amino acids isoleucine, leucine, and valine on the over-all synthesis of isoleucine from threonine and pyruvate in crude extracts from Escherichia coli were studied.

An assay method for isoleucine synthesized in vitro from radioactive threonine and a method for the isolation of dinitrophenyl isoleucine using thin-layer chromatography on silica gel are described. $K_{m}$ values were $12.0 \mathrm{mM}$ for threonine and $9.1 \mathrm{mM}$ for pyruvate.

The inhibition of the synthesis of isoleucine by isoleucine, leucine or valine was of an allosteric type. Isoleucine was the most effective inhibitor of the three, followed by leucine and valine in that order. No inhibition was observed with serine, alanine or aspartic acid.
\end{abstract}

The biosynthesis of isoleucine, leucine, and valine is catalyz by five common enzymes whose formation is controlled by a multivalent repression mechanism.1,2 It is also known that these three branched chain amino acids are antagonistic to each other in vivo and that the antagonistic effects depend on the test organism. ${ }^{3}$

The in vitro synthesis of isoleucine from 2-oxobutyrate and pyruvate from Neurospora crassa and Salmonella typhimurium was shown by Wagner and his coworkers.4,5 They estimated the conditions favoring the synthesis of isoleucine and valine in vitro and presented evidence that the enzymes needed in the synthesis are located in the membrane of the cell.

The kinetics and the effects of branched chain amino acids on the overall synthesis of isoleucine, leucine or valine in vitro have not been investigated. The present paper deals with the synthesis in vitro of isoleucine and with the effects of branched chain amino acids on the synthesis. Kinetic data are presented.

\section{MATERIALS AND METHODS}

Cell extract. A wild-type Escherichia coli U5-41 was transferred and cultivated for the inoculum as described earlier. ${ }^{6}$ The cells were grown in a simple glucose-mineral salt medium and harvested at the mid-point of the exponential growth phase. The culture

Acta Chem. Scand. 24 (1970) No. 8 
was shaken in a rotatory shaker (model A from E. Buehler, Tübingen, Germany) at 200 rpm at $37^{\circ}$ until the cells were harvested. The harvested cells were washed once with

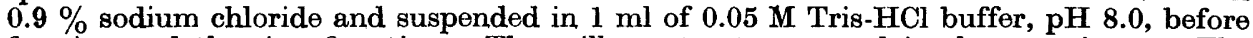
freezing and thawing five times. The milky extract was used in the experiments. The protein content of the dispersion was usually $20-30 \mathrm{mg} / \mathrm{ml}$.

Protein estimation. Protein contents were estimated by the method of Lowry et al. using serum albumin as standard. ${ }^{7}$

Reaction mixture. The synthesis in vitro of isoleucine from radioactive $\mathrm{L}_{-}$-threonine and non-radioactive pyruvate was followed. The reaction mixture, volume $0.2 \mathrm{ml}$, contained $2 \mu$ moles of magnesium sulfate heptahydrate, $0.06 \mu$ moles of thiamine pyrophosphate, $0.06 \mu$ moles of pyridoxal-5'-phosphate, $6 \mu$ moles of sodium L-glutamate, $20 \mu$ moles of sodium pyruvate, $0.33 \mu$ moles of glucose- 6 -phosphate, $0.125 \mu$ moles of NADP, 0.7 units ( 1 unit $=1 \mu \mathrm{mole} / \mathrm{min}$ substrate converted at $25^{\circ}$ ) of glucose-6-phosphate dehydrogenase and $2.5 \mu$ moles of Tris- $\mathrm{HCl}$ buffer, $\mathrm{pH}$ 8.0. The content of $\mathrm{L}_{-}$-threonine in the reaction mixture was $10 \mu$ moles and the amount of uniformly labelled $\mathrm{I}_{\text {- }}$-threonine was $0.0125 \mu$ moles $(0.125 \mu \mathrm{Ci})$. The reaction was started by pipetting a crude extract into $0.1 \mathrm{ml}$ of the reaction mixture.

Estimation of isoleucine. After $2 \mathrm{~h}$ incubation at $30^{\circ}, 1.0 \mathrm{ml}$ of $2 \%$ sodium carbonate solution was added and the resulting solution was mixed well and centrifuged at $10000 \mathrm{~g}$ for 10 min. A 25- $\mu 1$ sample of the supernatant was taken for the estimation of the total radioactivity of the reaction mixture. The remaining supernatant was transferred to a $20 \mathrm{ml}$ test tube and $2 \mathrm{ml}$ of ethanol solution containing $0.05 \mathrm{ml}$ of $0.3 \%$ dinitrofluorobenzene solution was added. The mixture was incubated with shaking at $37^{\circ}$ in a dark room for $1 \mathrm{~h}$. After the incubation, $5 \mathrm{ml}$ of water was added. The tube was extracted manually twice with $3.0 \mathrm{ml}$ of ether for $30 \mathrm{sec}$ and the ether extracts were discarded. The remaining water phase was acidified with two drops of $6 \mathrm{~N}$ hydrochloric acid and the mixture was extracted three times with ether. The ether extracts were combined and the ether evaporated in a vacuum desiccator. The residue was suspended in $1.5 \mathrm{ml}$ of acetone, the suspension was transferred to a small tube and the solvent was evaporated. The residue was resuspended in $0.2 \mathrm{ml}$ of ice-cold acetone and two $25 \mu \mathrm{l}$ aliquots were pipetted onto Whatman SG-81 paper. The fractionation of amino acids was carried out by the ascending technique using benzene-pyridine-glacial acetic acid (40:10:1) as solvent. The time needed for the separation was usually about $9 \mathrm{~h}$. The yellow isoleucine spot was cut out and the radioactivity was measured in a scintillation counter (Decem-NTL-314, Wallac Co., Turku, Finland) using a PPO-MSB solution as scintillation solution. A mixture containing all the reaction components that had not been incubated at $30^{\circ}$ served as a blank.

Reagents. All the reagents were of commercial origin: thiamine pyrophosphate from Hoffmann-La Roche, SA, Basel, Switzerland, pyridoxal-5'-phosphate (purum), glucose-6phosphate (purum) and L-threonine from Fluka AG, Buchs, Switzerland, L-glutamate, sodium pyruvate and dinitrofluorobenzene from E. Merck AG, Darmstadt, Germany, NADP and glucose-6-phosphate dehydrogenate from C. F. Boehringer \& Soehne GmbH, Mannheim, Germany. The radioactive amino acid, L-threonine-C-14 (U), code CFB 19, was purchased from the Radiochemical Centre, Amersham, England. The scintillation solution was prepared from Omnifluor-packages (Nen Chemicals GmbH, Frankfurt a.M., Germany) which contained a mixture composed of $98 \%$ 2,5-dinitrophenyloxazole (PPO) and $2 \% p$-bis-(o-methylsteryl)-benzene (MSB) of which $4 \mathrm{~g}$ was dissolved in one liter of toluene.

\section{RESULTS}

Linearity of isoleucine synthesis in time. Fig. 1 shows the rate of synthesis of isoleucine from pyruvate and threonine in vitro as a function of time at $30^{\circ}$. The rate in this experiment was $0.039 \mu$ moles of isoleucine per $\mathrm{mg}$ of protein per hour.

The incubation time was usually $2 \mathrm{~h}$ to get higher numbers of counts per minute.

Acta Chem. Scand. 24 (1970) No. 8 


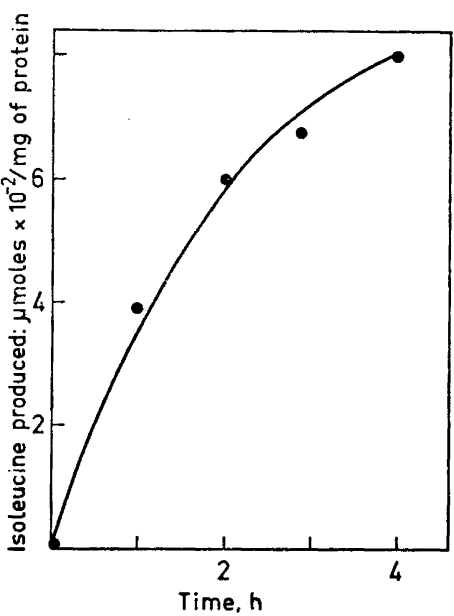

Fig. 1. Production of isoleucine from threonine and pyruvate in a crude extract from Escherichia coli. The reaction mixture contained $1.9 \mathrm{mg}$ of protein. The total radioactivity of the reaction mixture was 234800 cpm and that of the isoleucine after onehour incubation $1732 \mathrm{cpm} .1 .5 \%$ of the threonine carbon was converted to isoleucine carbon during a four-hour incubation.

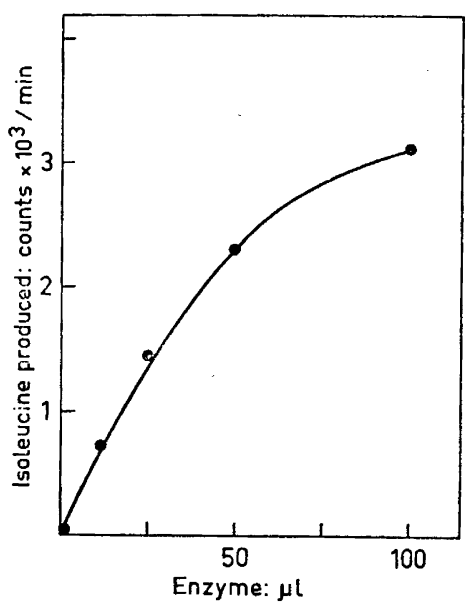

Fig. 2. The effect of protein concentration on the rate of isoleucine synthesis from pyruvate and $\mathrm{L}$-threonine. The crude extract contained $23 \mathrm{mg} / \mathrm{ml}$ of protein, and the time of reaction was $2 \mathrm{~h}$.

Dilution effect. When the effect of the amount of the crude extract in the reaction mixture was tested, the results presented in Fig. 2 were obtained. The initial rate of the reaction is a linear function of protein concentration up to $1 \mathrm{mg}$ of protein in the reaction mixture. Initial rates were determined in the experiments.

Involvement of cofactors. That the synthesis of isoleucine in vitro was the actual reaction was checked by omitting compounds from the reaction mixture. The results are presented in Table 1 .

Table 1 shows that the omission of each of the compounds tested reduced the rate of reaction. Hence isoleucine was synthesized. Additional proof was provided by inhibition studies where addition of $10 \mathrm{mM}$ cold unlabeled isoleucine solution almost stopped the transfer of radioactive carbon from threonine to isoleu cine.

When the crude extract was exposed to ultrasonic radiation for $3 \mathrm{~min}$ in a sonic oscillator (model DF-101, $250 \mathrm{~W}, 10 \mathrm{kc}$, Raytheon Co., Waltham, Massachusetts) and centrifuged at $100000 \mathrm{~g}$ for $1 \mathrm{~h}$ in an MSE ultracentrifuge (Measurement and Scientific Equipment Ltd., London, England), the supernatant, S-100, was not as active as the crude extract. This indicates that, as proposed earlier by Wagner et al. ${ }^{5}$ and by Cronenwett and Wagner, ${ }^{4}$ the main active matter is not located in the supernatant fraction. 
Table 1. Requirements for the over-all synthesis of isoleucine in crude extracts of $E$. coli. Isoleucine synthesis is expressed as percent of the activity in the complete system. The reaction mixture contained $10 \mu$ moles L-threonine and $1.9 \mathrm{mg}$ protein. The total radioactivity of the isoleucine fraction of the complete reaction system was $1575 \mathrm{cpm}$ after $2 \mathrm{~h}$ incubation at $30^{\circ}$.

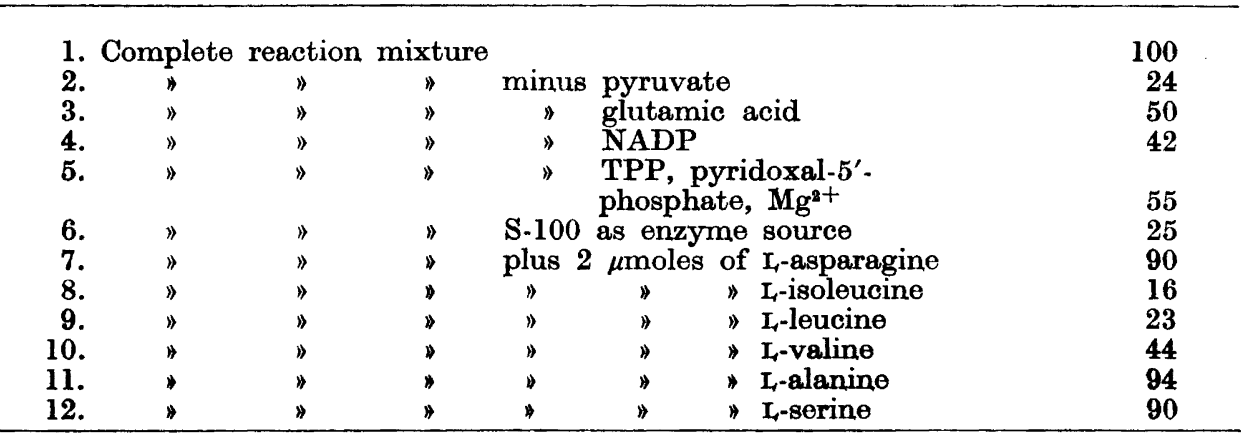

Effect of amino acids on the synthesis of isoleucine. Table 1 shows also the effects of certain amino acids on the synthesis of isoleucine from radioactive $\mathrm{L}$-threonine. The concentration of each $\mathrm{L}$-amino acid in the reaction mixture was $10 \mathrm{mM}$. The synthesis was most effectively inhibited by isoleucine, leucine, and valine. The inhibition by aspartic acid was not so marked as reported by Umbarger. ${ }^{8}$ Practically no inhibition was observed with alanine and serine.

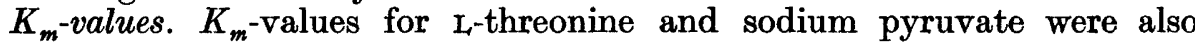
estimated. The values are presented in Fig. 3 and 4.

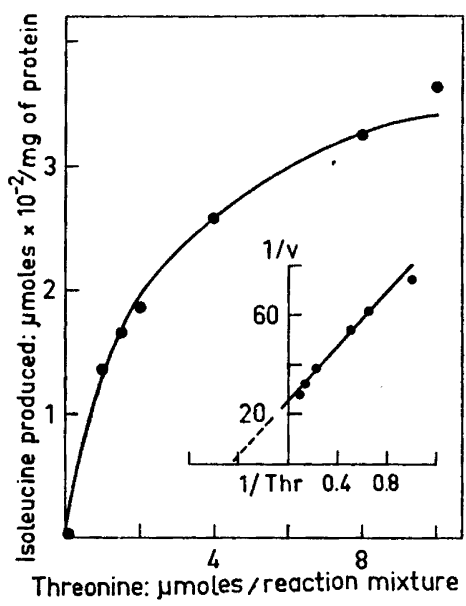

Fig. 3. Effect of threonine concentration on the rate of enzymic synthesis of isoleucine in a crude extract of $E$. coli.

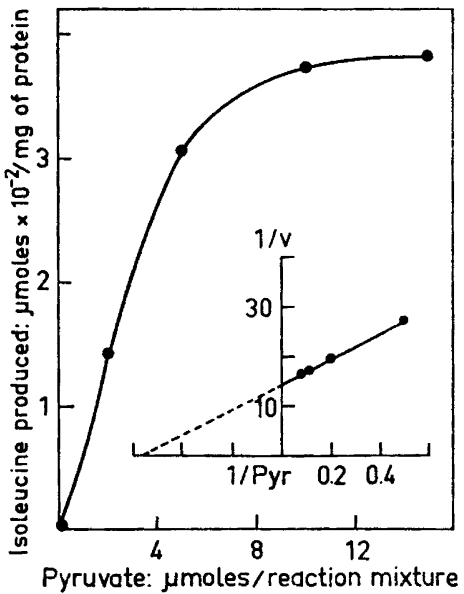

Fig. 4. Effect of pyruvate concentration on the rate of synthesis of isoleucine in a crude extract of $\boldsymbol{E}$. coli.

Acta Chem. Scand. 24 (1970) No. 8 
The enzymic reactions in the experiments where the crude extract was the enzyme source followed Michaelis-Menten kinetics. The $K_{m}$-values were calculated from the double reciprocal plot. The value $12 \mathrm{mM}$ was obtained with $L_{-}$-threonine as substrate and the value $9.1 \mathrm{mM}$ with sodium pyruvate as substrate.

Effect of isoleucine, leucine, and valine on the synthesis of isoleucine. To determine the type of inhibition and to evaluate the inhibition constants $K_{i}$ of the branched chain amino acids in the in vitro synthesis of isoleucine from
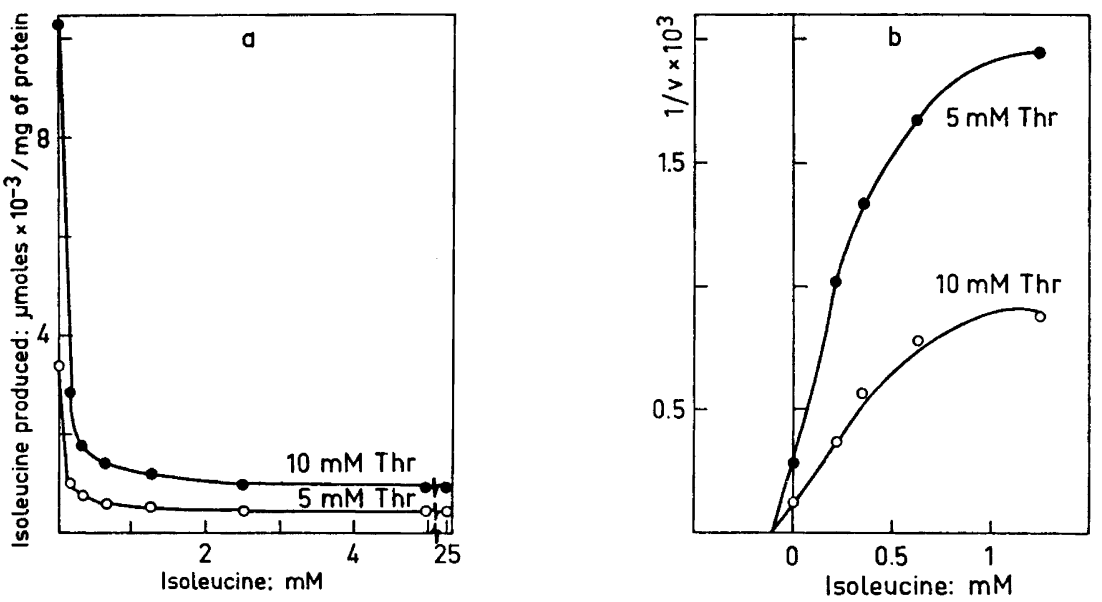

Fig. 5. The over-all rate of synthesis of isoleucine from threonine and pyruvate in a crude extract of $E$. coli as a function of added isoleucine concentration.
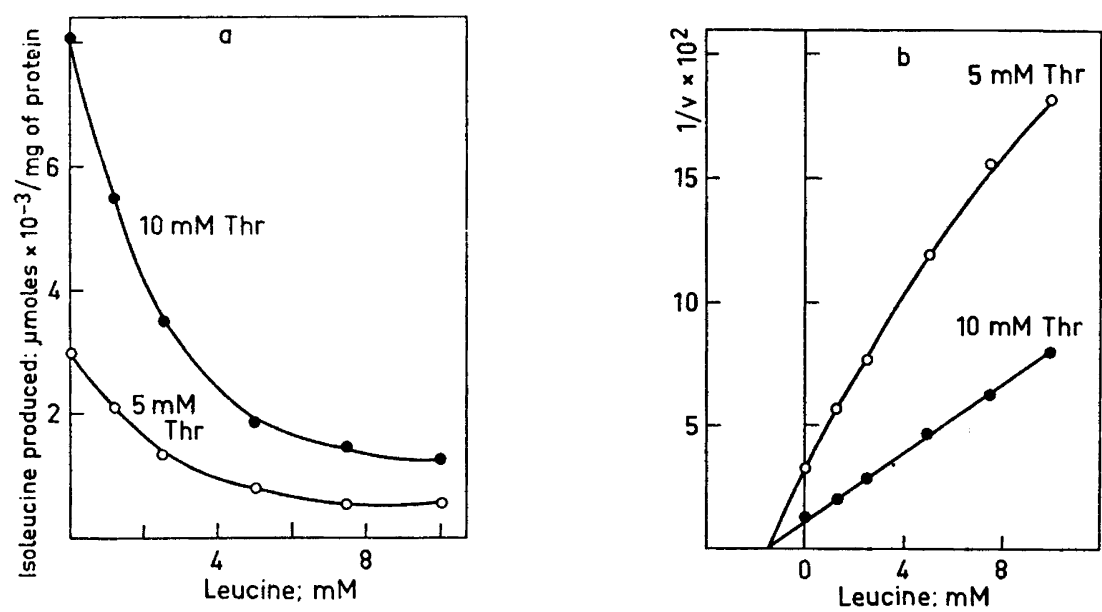

Fig. 6. The effect of added leucine on the formation of isoleucine from threonine and pyruvate in a crude extract of $\boldsymbol{E}$. coli.

Acta Chem. Scand. 24 (1970) No. 8 
uniformly labeled L-threonine, two threonine concentrations, 5 and $10 \mathrm{mM}$, were used. The interpretation of the kinetic data was based on the use of Dixon's plot. The results are presented in Figs. 5-7.
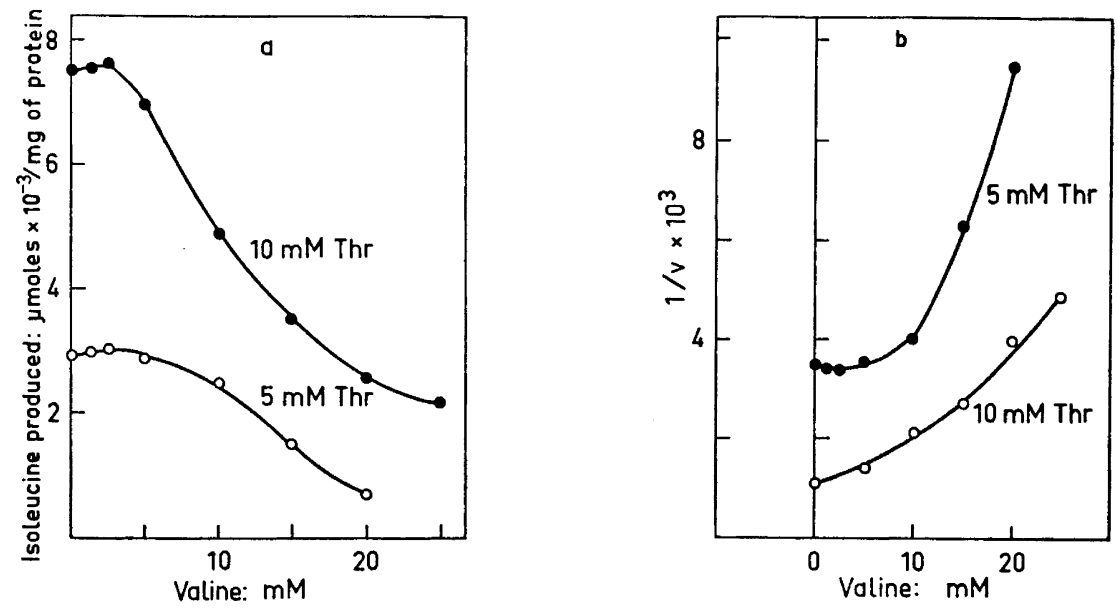

Fig. 7. The dependence of the rate of synthesis of isoleucine from threonine and pyruvate in vitro on the concentration of valine in the reaction mixture.

One can see from these figures that isoleucine is the most effective inhibitor (Fig. 5). The $K_{i}$-value is $9.4 \times 10^{-5} \mathrm{M}$ and the type of inhibition is very nonlinear. Even a $25 \mathrm{mM}$ isoleucine conceñtration did not effect $100 \%$ inhibition at $5 \mathrm{mM}$ or $10 \mathrm{mM}$ L-threonine concentrations. Similar results were obtained with leucine and valine. The $K_{i}$-value for leucine was $1.6 \times 10^{-3} \mathrm{M}$ (Fig. 6).

A quite different inhibition was that of valine (Fig. 7). A low valine concentration caused a slight activation, but concentrations higher than $2 \mathrm{mM}$ led to inhibition.

\section{DISCUSSION}

The rate of synthesis of isoleucine from radioactive threonine and nonradioactive pyruvate was usually of the order of $0.04 \mu$ moles per mg of protein per hour at $30^{\circ}$ (Fig. 1). This rate is of the same order as that reported by Cronenwett and Wagner ${ }^{4}(0.063 \mu$ moles of isoleucine produced per hour per $\mathrm{mg}$ of protein at $37^{\circ}$ ). When the rate of synthesis in vitro (Fig. 1) is compared with the rate in vivo reported by Roberts et al. ${ }^{9}(4.6 \mu$ moles of isoleucine synthesized per $g$ of dry weight per 100 seconds at $37^{\circ}$ ), the rate in vitro is about $14 \%$ of the rate in vivo, if it can be assumed that dry $E$. coli cells contain $59 \%$ protein and if the difference in temperature can be disregarded.

The optimal concentrations of all the components involved in the over-all synthesis of isoleucine were not determined. Only the $K_{m}$-values for threonine and pyruvate were estimated (Figs. 3 and 4 ). The omission of certain compounds from the complete reaction mixture, however, lowered the activity 
about $50 \%$ and confirmed that the assay conditions were correct. Table 1 shows that the supernatant fraction separated by $100000 \mathrm{~g}$ during $1 \mathrm{~h}$ had a very low activity. Cronenwett and Wagner ${ }^{4}$ suggested that the four enzymes needed in the synthesis of isoleucine are located as a multienzyme package in the cell membrane. The results in Table 1 support this assumption.

The $K_{m}$-values for $\mathrm{L}_{1}$-threonine estimated as shown in Fig. 3 was $12.0 \mathrm{mM}$. The content of threonine in the amino acid pool of the exponentially growing Escherichia coli has been estimated to be $0.2 \mu$ moles per gram of dry weight and thus the concentration of the amino acid in the cell is about $6 \mu \mathrm{M} .10$ When this value was calculated it was assumed that the dry weight of $E$. coli cells is $25 \%$ of the wet weight and that the cell density is unity. ${ }^{9}$ The content of threonine is very low in the cell and because the reaction followed MichaelisMenten kinetics, the changes in the threonine concentrations in vivo should lead to corresponding changes in the rates of isoleucine synthesis. The content of isoleucine in the same pool was $41 \mu \mathrm{M} .{ }^{10}$ Isoleucine is thus a very effective feedback inhibitor, because Fig. 5 shows that the $K_{i}$-value is $94 \mu \mathrm{M}$. It is therefore reasonable to assume that the synthesis of isoleucine in vivo is controlled by the end product.

It can be seen also from Figs. 5- 7 that none of the inhibitors, isoleucine, leucine or valine, lowers the activity to zero. In the case of isoleucine, the highest concentrations lower the activity to about 1/10th of the uninhibited value. The reduction is even greater when leucine or valine is the inhibitor. Valine at low concentrations stimulates the isoleucine synthesis. The similar observations with threonine deaminase suggest that this enzyme is the key factor controlling isoleucine synthesis. Threonine deaminase is not fully inhibited by isoleucine in certain Escherichia coli strains, especially wild ones, but there are mutants where the inhibition of threonine deaminase by isoleucine is complete. ${ }^{11,12}$ The observation that branched chain amino acids cannot stop the transfer of carbon from threonine to isoleucine may explain the inactivity of leucine and valine in the wild type of $E$. coli.

\section{REFERENCES}

1. Freundlich, M., Burns, R. O. and Umbarger, H. E. Proc. Natl. Acad. Sci. US 54 (1965) 1804.

2. Raunio, R. Ann. Acad. Sci. Fennicae A II 127 (1964). Thesis.

3. Holden, T. J. Amino Acid Pools, Elsevier, Amsterdam 1962, p. 12.

4. Cronenwett, C. S. and Wagner, R. P. Proc. Natl. Acad. Sci US 54 (1965) 1643.

5. Wagner, R. P., Bergquist, A. and Barbee, T. Biochim. Biophys. Acta 100 (1965) 444.

6. Raunio, R. Acta Chem. Scand. 22 (1968) 2733.

7. Lowry, O. H., Rosenbrough, N. J., Farr, A. L. and Randall, R. J. J. Biol. Chem. 193 (1951) 265.

8. Umbarger, H. E. Science 123 (1956) 848.

9. Roberts, R. B., Abelson, P. H., Cowie, D. B., Bolton, E. T. and Britten, R. J. Studies of Biosynthesis in Escherichia coli, Carnegie Institutions of Washington Publication 607 , Washington DC 1957, pp. 5 and 420 .

10. Raunio, R. and Rosenqvist, H. Unpublished data.

11. Changeux, J.-P. Cold Spring Harbor Symp. Quant. Biol. 26 (1961) 313; 28 (1963) 497.

12. Datta, P. J. Biol. Chem. 241 (1966) 5836; 244 (1969) 858.

Received February 12, 1970.

Acta Chem. Scand. 24 (1970) No. 8 